\title{
INTERNATIONAL CO-OPERATION IN MARINE RESEARCH
}

$\mathrm{M}$ ARINE science is growing in usefulness and begins to attract more support from international as well as national authorities.

Unesco initiated a Marine Sciences Programme in 1955 with the establishment of an International Advisory Committee on Marine Sciences chosen from countries in all parts of the world to represent all aspects of the subject. The main object of the programme is to cultivate interest in the oceans, particularly in countries whore scientists are not being very active about them, and while this work takes shape limited funds are available from time to time to stimulate international or regional co-operation in work likely to increase world interest and to make the early stages of the work more effective.

The advisory committee tries to hold its meetings in countries where there is a small nucleus of marine scientists ready to take advantage of the influx to diseuss work being done in the region, and symposia on regional problems are arranged. One of the most direct methods of achieving the educational and cultural aims is to provide visiting lecturers and travel. ling fellowships. Short courses have been held at suitable laboratories, for example, a three-weeks course in planktology at Nhatrang in 1956, and more ambitious schemes are being planned.

While these plans are taking shape, grants have been made to a number of symposia arranged by organizations such as the Association of Physical Oceanography and the International Council for the Exploration of the Sea on the most prominent topics of the day. They have included symposia on ocean circulation and on the measurement of primary productivity in the ocean. 'The Association of Physical Oceanography has been granted a useful sum to facilitate participation by Norway in a joint operation with the United Kingdom and United States to develop and use techniques for measuring deep currents in mid-Atlantic Ocean. Another sum is being used to help scientists from Australia, New Zealand and New Caledonia to lay the foundations for a study of the surface currents and water circulation in the south-east Pacific Ocean and the Tasman Sca.

Unesco is also organizing practical study of the feasibility of joint ownership of research vessels by groups of countries. This seems to be the only answer to the growing cost of maintaining oceangoing research ships. Sooner or later it must be done, and the possibility of a trial venture in the Indian Ocean is being explored. Further tasks have been the assembly of advice and material from competent organizations and scientists on the oceanographic problems bearing on sea and ocean disposal of atomic wastes, and a sirnilar assessment of the scientific considerations relating to international laws designed to govern continental shelves.

Unesco is an ideal organization for cultivating enthusiasm in subjects of educational and cultural value, and the liberal study of the oceans is as good a discipline as any. There is no better field in which to promote mixing of ideas and free exchange of views, and the headquarters and area offices of Unesco know how to go about it.

The International Council of Scientific Unions, to which Unesco makes a large annual grant, is just as suitable for advancing research at higher levels. It encourages and co-ordinates activities of the intor- national scientific unions and furthers common effort in subjects inadequately covered by existing arrange ments.

The International Council of Sciontific Unions has responded to the needs of marine science by sotting up a Special Committee on Oceanic Research, which met for the first time in Woods Hole Oceanographic Institution, Woods Hole, Mass., during August 28-30. The following were present: Dr. A. Bruun (Denmark), Dr. G. Böhnecke (Germany), Cdr. R. A. Capurro (Argentina), Dr. G. E. R. Deacon (United Kingdom), Dr. M. N. Hill (United Kingdom), Dr. C. O'D. Iselin (United States), Dr. N. B. Marshall (United Kingdom), Dr. Y. Miyake (Japan), Prof. H. Mosby (Norway), Dr. N. W. Rakestraw (United States), Dr. R. Revelle (United States), Prof. Steemann Nielson (Denmark) and Prof. L. Zenkeviteh (U.S.S.R.). Prof. Y. Le Grand (France) and Dr. N. K. Pannikar (India) were unable to attend. Two days wero spent discussing outstanding problems in all aspects of the subject with the purpose of finding which could be most helped by planned co-operation between many countries. Although the Committes sometimes regretted the absence of one specialist or another, it was adoquate, with some timely reinforcement from the Woods Hole Laboratory and its wealth of visiting scientists, to make the occasion a memorable one.

The outcome was a general agreement that there is a real need for international collaboration in studying the deep oceans. Theoretical studies and the development of new techniques are likely to succeed well enough in individual laboratories and in co-operative effort between major institutions bordering on common ocean areas and having joint interests, but the task of sending expeditions to distant parts of the ocean, even to areas which promise the best conditions for studying basic problems, becomes increasingly difficult for any country. Wo know something of every ocean, but there are large fairly blank areas where modern ideas and methods are not likely to be applied until the cost and effort are widely shared.

Among the new techniques which should be used are: (1) measurement of salinity of tho deep and bottom waters with the new ordor of precision made possible by electrical conductivity measurements; (2) direct measurement of the deep currents with free-drifting floats or moored current meter's ; (3) use of the distribution of naturally occurring radioactive? substances as indicators of circulation and mixing : (4) quantitative biological, chemical and physical studies of the sediments; (5) measurement of heat flow from the earth to the water; (6) studies of the carbon dioxide content and the exchanges between ocean and atmosphere. 'The well-tried methods so far' used in biological studies must also be supplemented by recent photographic and acoustic tochniques. 'These and other advances that can be expected during the next few years require the use of ships fitted for deep-sea exploration. This is the most expensive kind of oceanographic research, and an adequate programme is beyond the resources of any one country.

The Special Committee on Oceanic Research judged that the best way to start is to devote the next two or three years to organized attempts by working groups to review the special problems that will be 
tackled, to widen the acceptance and use of promising techniques and to fill gaps so far as possible. By the end of this preparatory period it should be possible to gather sufficient ship-time and funds together to make a combined assault on one of the least-known and most promising areas. The Indian Ocean was thought to fill this requirement. Its submarine topography and water circulation are not very well known ; the complete reversal of wind in two halves of the year affords a unique opportunity for studying how quickly the currents and water layers respond to wind changes, and there is much biological and geological work to be done.

Such a programme cannot be carried out without enthusiastic support of existing national and international organizations, and fairly immediate practical aims must be urged as well as long-term need for better understanding of the oceans. One growing need is for a better appreciation of the effect of using the oceans as a receptacle for the waste products of industry. Even now we need to know what effects the water circulation and the migrations of marine animals are likely to have on the transport of radioactive material deposited in the ocean. We no longer look on the oceans as infinite and readily available sources of food, but we are more and more conscious that better understanding of their physies and biology will be a great help to the successful use of their tapped and untapped resources. The study of elimate and weather has also advanced to the stage where it begins to need more understanding of the circulation of heat in the oceans and their interchanges with the atmosphere.

The idea of making a start in the Indian Ocean is likely to receive the approval of most international authorities interested in the oceans. Unesco will have opportunities to arrange the training of scientists from countries around the Indian Ocean, and to make the possibilities known to more countries. The Food and Agriculture Organization is very interested in the striking fluctuations in the fisheries in the northern part of the Ocean, and their effect on the local populations. The scientific unions will recognize the value of now and widespread measurements to basic as well as to the regional problems.

The idea will not go unchallenged. There are not many oceanographers, and they are not likely to welcome new obligations. It was not easy for oceanography to take part in the International Geophysical Year. The scheme that is gradually being formulated is, however, a reasonable plan, with plenty of encouragement for individual effort and inter-laboratory collaboration, as well as measures for promoting co-operation on a larger scale than can be achieved without special organization. The plan is also arranged to take full advantage of the knowledge and experience of existing organizations such as the scientific unions, which are mainly concerned with basic studies of particular aspects of the subject, and the regional associations such as the International Council for the Exploration of the Sea, the Pacific Science Council, and others, which grow in importance but are primarily concerned with regional problems. One of the fears most expressed is that there is too much overlapping between all the new and old interests, and too many conferences. As the subject grows we must work for some unification, but it is only fair to admit that there has been so far no forum in which specialists in all aspects of the subject meet together, and we already see growing enthusiasm and sharing of responsibilities.

G. E. R. Deacon

\section{THE TECHNICAL ASSISTANCE BOARD REPORT FOR 1956}

$T$ HE annual report of the Technical Assistance Board for 1956* to the Economic and Social Council of the United Nations records that a higher initial earmarking of funds for the participating organizations and the secretariat-up to 97.3 per cent of the approved programme, compared with only 56 and 71 per cent, respectively, in 1954 and 1955 - with consequent smoother implementation of the programme, was possible ; also that 93 per cent of the programme was delivered to the centres requesting assistance during the year. Of the $25 \cdot 3$ million dollars expended on field operations during 1956, 18 per cent was for the 2,128 fellowships, including study grants awarded, for which 88 countries served as hosts ; 13 per cent on equipment and supplies for training and demonstration; and the remaining 69 per cent to finance the 2,346 experts supplied. These experts were drawn from sixty-seven nationalities, and despite difficulties in recruitment in certain specialized fields, this total is 238 higher than in 1955; the professional standard was maintained at a high average level, although there are indications that the Expanded Programme does not offer conditions of service adequate to attract men and women of the quality desired in the absence of idealistic motives.

Technical assistance was provided in fifty-six sovereign States and in forty-seven dependent territories; but soundly based requests for technical assistance greatly exceed in volume the possibilities of meeting them, and the report suggests that even if increased resources become available it may be wise to concentrate on the neediest countries and territories. Some adjustments in the geographical distribution have already been made : in 1954, VietNam, Cambodia, Laos, Sudan, Tunisia, Morocco and Ghana received technical assistance under the Expanded Programme amounting to 240,000 dollars ; in 1956 they received 780,000 dollars, and for 1957 it will be about 1.5 million dollars. In many of the less-developed countries, requests for assistance place increasing emphasis on the development of adminis. trative and technical services. The ability of a country to develop its resources and to take full advantage of technical assistance depends largely on the stage of development of its government and administration, and increasing attention is likely to be given to this aspect as the resources of the programme expand.

The Technical Assistance Board is examining the high proportion of continuing projects-915 out of the 1,334 projects in operation in 1956 were started in 1955 or earlier-with reference to the possibility that the programme as a whole is becoming rigid. The continuing programmes accounted for 85 per cent of the expenditure on the field-programme, but this was largely due to the overlapping of programme years, although there are a few genuine long-term projects. Nevertheless, the chapter on evaluation of the programmes introduced this year is intended to be a regular feature of future annual reports, and it is hoped that governments will co-operate in pro-

* Annual Report of the Technical Assistance Board for 1956. Pp. 244. (New York: United Nations, 1957.) 